\title{
Reproductive behavior of the european roller (Coracias garrulus Linnaeus, 1758)
}

\author{
Liubov Malovichko ${ }^{1}$, Nadezhda Poddubnaya ${ }^{2, *}$, Karina Akimova ${ }^{3}$, Liubov Eltsova ${ }^{2}$ \\ ${ }^{1}$ Russian State Agrarian University - Moscow Timiryazev Agricultural Academy, Russia \\ ${ }^{2}$ Cherepovets State University, Cherepovets, Russia \\ ${ }^{3}$ V. N. Karazin Kharkiv National University, Ukraine
}

\begin{abstract}
In the European part of Russia, there is a decrease in the area and number of the European Roller. We performed a preliminary study of the role of behavioral ecology in the survival of the species. The material was collected in the Stavropol krai in 2004, 2006-2019. Females and males were distinguished by color intensity (females' plumage is paler) and behavior. Birds exhibit complex biocommunication with features of a foraging economy, distribution of parental roles, and high coordination of partner actions. Additional research is needed to elucidate the behavior of birds whose partners died in the flyover or wintering areas.
\end{abstract}

\section{Introduction}

The problem of biodiversity conservation on the planet is one of the hot spots in science (e.g. [1]). The conservation of each endangered species often exhibits a mystery and different ways of solving it. The list of such species includes the European roller (Coracias garrulus (Linnaeus, 1758)) [2]. In the middle of the XX century the European roller has disappeared in a number of European countries and in several more - negative trends are observed [3]. In the European part of Russia, there is also a reduction in the range and number of the species [4]. The main threats faced by the European roller are: changes in the environment associated with agriculture, the loss of suitable nesting sites, a reduction in the food supply due to an increase in the level of toxicants in the environment, and illegal hunting [5]. At the same time, there is practically no information about the place of behavioral ecology in the survival of the species. The aim of our work was to try to fill this gap.

\section{Materials and Methods}

The material was collected in the Stavropol krai $\left(46^{\circ} 14^{\prime} \mathrm{N}-43^{\circ} 59^{\prime} \mathrm{N}\right.$ and $40^{\circ} 48^{\prime} \mathrm{E}-$ $45^{\circ} 47^{\prime} \mathrm{E}$ ). The area of the region is $66160 \mathrm{~km}^{2}$ and is comparable to the territories of countries such as Lithuania and some others. The region is located in the steppe and semidesert zone, and partly in the forest-steppe foothills and subalpine foothill meadows. Data on reproductive behavior [6,7] were obtained in 2004 and 2006-2019. When we saw

\footnotetext{
* Corresponding author: poddoubnaia@mail.ru
} 
individuals, we recorded breeding status according to the European Bird Census Council (EBCC) [8] and considered those that were classified as probable and confirmed. The species is considered not dimorphic; in fact, females are not as brightly colored as males and an experienced observer can easily identify the sex.

\section{Results and discussion}

Birds arrive in the region at the end of April - approximately at the same time as in other places at this latitude [9]. And usually in mid-May they occupy a nesting territory of about radius distance in $50 \mathrm{~m}$, which is mainly guarded by a male already during the courtship period and then during breeding. They inform the emerging stranger male about her employment with air somersaults. Both males soar into the sky almost vertically upward, suddenly stop in the air, "dive" downward, "wobbling" and gaining speed, then align in one line, rotate their bodies to the left and to the right relative to their axis. The rotation is accompanied by a hoarse cry "ruck-ruck-ruck-ruck". Both males can repeat the ascents several times without interruption. This behavior occurs during courtship and mating, sometimes in the later stages of breeding. From time to time, males can show aggression, expelling strangers from their territory. With long-term observation, it is noticeable that the territories of neighboring pairs can overlap $[10,11]$.

The female can also do somersaults with her male. Quite often a couple makes such somersaults even in the absence of strangers / other birds. At the same time, the male sharp fly-up to $200-250 \mathrm{~m}$ and at the same time beats its wings strongly and publishes several slow cries of "ruck-ruck", then he almost freezes in the air, turns and abruptly "dives" down, flapping his wings and side to side. On the descent, it emits a series of crackling screams. After such flights, ritual feeding begins. The feeding of the female by the male begins several days before egg-laying and continues until its completion. During this period, the female sometimes feeds the male.

Mating begins 3-5 days before egg-laying and stops before clutch is complete. Birds mate on the perch next to the nest. Shortly before mating, the partners sit on the perch and clean each other's feathers. Then they jerk their beaks up and alternately emit "kakak" cries, similar to the sound of the hammering of wooden bars against each other, or similar to the croaking of a rook, but in a higher tone, then the female makes another cry, very loudly "rakkiri-rakkiri-rakkiri ". This sound "rakkiri-rakkiri-rakkiri" is also emitted by the male very loudly just before mating, giving the observer the impression of a contract of agreement between the birds.

Broodiness begins before the end of clutching and occurs mainly from the third decade of May to the end of June. Incubation lasts 17-19 days. At night, the female incubates the clutch; during the day, the mating birds often change. At the beginning of incubation, the female flies out of the burrow to feed; at this time, the male feeds the female very rarely, on average once a day [11]. After the clutch is completed, dense incubation begins, the male feeds the female up to 8 times a day.

Feeding of the female by the male during this period is as follows. The male with food sits down near the burrow. The female flies out of it and utters a cry "kee-kee-kee", trying to take food from him. The male gives the female prey, which he had previously killed, a large prey: dragonflies, beetles, frogs, he several times hit on the perch apparently, for softens. The female, having received food, flies to another perch, where she eats it. After feeding, the female returns to the nest or is replaced by a male.

During incubation, the male actively guards the nesting territory and drives away not only alien rollers, but also other large birds: rooks (Corvus frugilegus), marsh harriers (Circus aeruginosus), cuckoos (Cuculus canorus), hoopoes (Upupa epops). The European rollers also communicate with birds living in the neighborhood using voice 
signals.

Both parents take part in the feeding of the chicks, as well as in the incubation of the clutch. On average, each parent fed the chicks once an hour. Sometimes a couple has one helper in breeding, possibly from the brood of the previous year. There may be more such helpers [12].

The weather, apparently, have little effect on the intensity of feeding of the chicks, and only during a very heavy rain do parents less often fly up to the nest with food and, cowering, sit on the perch. After the rain, the birds intensively feed the chicks with the earthworms collected from the wet ground, making up for the interruption in feeding caused by the rain. The intensity of feeding the chicks depends not only on the weather and time of day, but also on the weight of the feed. So, if rollers hunted a snake or a lizard, and fed them to the chicks, then the feeding break was from 30 to 60 minutes.

The female showed caution - in case of danger and anxiety, she sat on the perch, looked around and waited for the danger to pass, and only after that flew into the hole with food. The male carried food into the hole, despite the danger.

The rollers usually hunt from perches up to $10 \mathrm{~m}$ above the ground, as in the entire range. Therefore, electrical wires and pylons are ideal for them (Table 1). Electric shocks from non-insulated medium voltage poles are dangerous to all species of birds. And death of rollers from electric shock has been recorded in different countries (eg, [13]). In the context of a decrease in the mosaicity of plant communities and the dominance of herbaceous forms, an increase in the number of birds on power lines can be expected.Use $170 \times 250 \mathrm{~mm}$ paper size (W $\times \mathrm{H} \mathrm{mm}$ ) and adjust the margins to those shown in the Table 1. The final printed area will be $130 \times 210 \mathrm{~mm}$. Do not add any page numbers.

Table 1. Use of different types of perch in the Stavropol krai by the European roller (Coracias garrulus) $(\mathrm{n}=100)$

\begin{tabular}{|l|c|}
\hline \multicolumn{1}{|c|}{ Perch type } & \% of all individuals on the perch \\
\hline Power transmission lines & 70 \\
\hline Forest belt & 12 \\
\hline A single living tree or shrub & 10 \\
\hline Dry wood & 2 \\
\hline Thickets of tamarisk (Tamarix L., 1753) & 2 \\
\hline Weed thickets & 2 \\
\hline Bumps & 1 \\
\hline Straw rolls & 1 \\
\hline
\end{tabular}

During the period of feeding the chicks, the married couple periodically maintain voice communication, signaling arrival or danger. Voice signals become more frequent in the post-nesting period and they are directed to both fledglings and adult birds. It should be noted that pairs that have been in the same nest for several years in a row demonstrate a high consistency of "songs" and other forms of behavior noted by observers. And it seems necessary to continue the study of biocommunications in the Stavropol population of Rollers using technical means (e.g., 14, 15) to better understand the role of behavior in the survival of these birds. In this monogamous species [11], one can expect not to enter into reproduction of individuals after the death of one of the partners, which, of course, can play a role in the decrease in the number of the local population. Outside the breeding grounds, birds of this can be hunted, and if one bird from the pair dies, then the second does not return to the breeding site. 


\section{Conclusion}

The European roller demonstrates complex biocommunication and behavioral ecology: the economy of foraging (generalists in nutrition, where and when to hunt for males and females), the economic foundations of territoriality, the benefits of collective feeding of offspring, the distribution of parental roles, and the coordination of partners' actions that increase reproductive success. Additional research is needed to elucidate the behavior of birds whose partners died in the areas of migration or wintering.

\section{References}

1. N. Kolomiytsev, N. Poddubnaya, Biological Communications, 63(3), 189-201 (2018)

2. Order of the Ministry of Natural Resources of Russia "On Approval of the List of Fauna Objects Included in the Red Book of the Russian Federation" No. 162 dated 03.24 .2020

3. Directive 2009/147 / EC of the European Parliament and of the Council of 30 November 2009 on the conservation of wild birds (Official text on EUR-Lex)

4. A. Mishchenko et al., Population estimates and its dynamics for birds of the european part of Russia (Russian Society for the Conservation and Study of Birds, Moscow, 2017)

5. J. Catry, A. Marcelino. F. Franco. Biodiversity and Conservation, 26(3), 2016.

6. G. Novikov. Field studies of the ecology of terrestrial vertebrates («Soviet Science, Moscow, 1953)

7. C. Bibby, M. Jones, S. Marsden. Expedition Field Techniques: Bird Surveys. (BirdLife International, Camdridge, 1998)

8. N. Arslan, G. Akveran, KSÜ Tarım ve Doğa Derg 22(5), 794-798 (2019)

9. J. Rodriguez-Ruiz et al., Bird Conservation International 29(1), 159-175 (2019)

10. A. Kovacs, B. Barov, C. Orhun, U. Gallo-Orsi, International Species Action Plan for the European Roller Coracias garrulus garrulus (2008)

11. L. Malovichko, V. Konstantinov. Ecology of burrowing birds. Environmental and morphological adaptations. (Moscow, 2000)

12. M. Casadei, P. Ceccarelli. Quaderno di studi e notizie di storia naturale della Romagna, 42, 2015.

13. B. Csibrány (ed.) Conservation of the European Roller (Coracias garrulus) in the Carpathian Basin (LIFE13/NAT/HU/000081).

14. I. Boehme, M. Goretskaya, J. of General Biology, 77 (3), 239-246 (2016)

15. A. Nikol'skii, V. Rumiantsev. Doklady Biological Sciences. 445(1), 261-264 (2012) 